\title{
The Potential of Simulation to Enhance Nursing Students' Preparation for Suicide Risk Assessment: A Review
}

\author{
Joanna Davison, Bev Mackay, Michael J. McGivern \\ NorthTec Nursing Department, Whangarei, New Zealand \\ Email: Jdavison@northtec.ac.nz,Bmackay@northtec.ac.nz,MMcGivern@northtec.ac.nz
}

How to cite this paper: Davison, J., Mackay, B. and McGivern, M.J. (2017) The Potential of Simulation to Enhance Nursing Students' Preparation for Suicide Risk Assessment: A Review. Open Journal of Nursing, 7, 129-144.

https://doi.org/10.4236/ojn.2017.72012

Received: November 23, 2016

Accepted: February 4, 2017

Published: February 7, 2017

Copyright $\odot 2017$ by authors and Scientific Research Publishing Inc. This work is licensed under the Creative Commons Attribution International License (CC BY 4.0).

http://creativecommons.org/licenses/by/4.0/

\begin{abstract}
Suicide risk assessment is a critical skill in preventing suicide. Yet most nurses do not feel confident in assessing suicide risk. Development of this potentially life-saving skill needs to begin at the undergraduate nursing level. As simulation is an effective pedagogical tool utilised within nursing education, the aim of this paper was to explore the potential of simulation in preparing student nurses' for suicide risk assessment. Literature was examined to identify what simulation modalities were employed within nursing education and the outcomes associated with these. The findings suggest that to varying degrees all simulation modalities have the potential to decrease student anxiety, and increase student confidence, knowledge and communication skills when working with people at risk of suicide. However the use of Standardised Patient (SP) simulation adds an authenticity to the experience and allows for the assessment of a wider range of human responses, including key nonverbal communication skills. The sense of realism provided by SP allows for more in-depth understanding into the person's experiences, which is critical in the assessment of a person's mental health needs and risk of suicide. The majority of simulations identified were located within a mental health setting. Given that student nurses may encounter a person who is suicidal in any clinical setting, further research is needed on simulation which integrates mental health assessments and suicide risk assessment into a variety of clinical areas.
\end{abstract}

\section{Keywords}

Mental Health, Student Nurses, Simulation, Suicide Risk Assessment

\section{Introduction}

The assessment of suicide risk is one of the most challenging tasks facing nurses 
in the current health care environment. Suicide is a serious public health and social issue and the suicide rates of a country are an indication of the mental health and welling of that population. According to the World Health Organisation [WHO] every 40 seconds a person in the world dies by suicide; and suicide prevention needs to be a high public health priority for all countries [1]. Among the OECD countries New Zealand has the second highest youth suicide rate, and young Maori men are disproportionately represented along with older men and rural farmers [2]. In 2016, annual suicide figures in New Zealand were the highest since coronial records began in 2006 and this followed the previous highest total recorded in 2015 [3]. Female suicide deaths also increased in 2016 and the ratio between female and male suicide rates was the closest for the first time [3]. The WHO Mental Health Plan 2013-2020 aims to reduce suicide rates in countries by $10 \%$ [4] and one key strategy identified in suicide prevention is the training of health care providers and the inclusion of suicide risk assessment within education curricula [1]. For nurses this training would begin at the undergraduate level, and the use of simulation may have a role in the development of these skills.

\section{Background}

Reducing the incidence of suicide begins with identifying those at risk. Following initial presentation indicating a need for a mental health triage, assessing suicide risk is one of the first steps in the triage process for front-line staff [5] [6]. According to the Ministry of Health [5] client presentation with self-harm, mental health issues or physical health and drug or alcohol toxicity can indicate potential risk, but suicidal intent may not be obvious. Initial assessment should focus on the immediate history of self-harm and suicidal thoughts, identifying urgency and level of risk; a more detailed suicide risk assessment can be arranged if necessary. Guidelines suggest that this initial assessment can take two forms: (i) a mental health assessment incorporating suicide risk assessment which takes into account not only what a person may relay to the interviewer, but also all expressive behaviour; and/or, (ii) direct questioning about suicidality [6]. Capability with both mental health assessment and suicide risk assessment prepares frontline staff to act to prevent suicide.

Nurses as the health professionals most seen at the fore front of health services are in a key position to prevent suicide; however, to enable nurses to act, nurses themselves need to feel confident in assessing for suicidal risk. Given that the majority of people who suicide have seen a health professional in the month before their death [7], it is highly likely that regardless of the health setting nurses will have to provide care for someone who is potentially suicidal. Yetnurses' report feeling unconfident and ill prepared to discuss suicide or suicidal ideation [8]. As a result people are rarely identified as being at-risk [9]. Education of nurses can support their preparation for assessing and caring for a suicidal person [9] and knowing how to identify an at-risk person and the level of risk is the first step in preventing suicide [10]. Development of these potentially life-saving 
assessment skills needs to begin in undergraduate nursing education. Student nurses need to be empathetic and understanding when working with a person at risk of suicide and confident in their communication skills and suicide risk assessment skills. According to Pullen, Gilje and Tesar [11] the extent of focus on suicide risk assessment in curricula is relatively unknown. In addition, many nursing students do not have the opportunity to be actively involved in suicide risk assessments on clinical placement [12]. As a potentially life-saving skill, suicide risk assessment skills are just as critical for undergraduate nurses as knowledge regarding cardiovascular disease and associated risk factors.

Before skills can be developed, attitudes towards people at risk of suicide must be challenged. Many studies suggest health professionals, including nursing students, hold negative attitudes towards people who are suicidal [13] [14] [15] [16]. As early as the 1990's it was identified that student nurses attitudes towards caring for people who were suicidal were positively influenced by using an alternative interactive teaching strategy rather than a traditional method of teaching [14]. Reliance on non-traditional approaches is not adequate to effect changes in student nurses' values and beliefs [17]. Simulation as a supplement to traditional teaching approaches, and designed around suicide risk assessment, has the potential to provide nursing students the opportunity to not only change attitudes but also to develop essential skills. Bolster et al. [9] suggest that with simulation being an integral part of nursing education at undergraduate level, simulation scenarios incorporating suicide assessment need to be routinely established and integrated into curriculum.

There is no doubt that simulation is an effective pedagogical tool within nursing education, however the term "simulation" can be applied to a variety of approaches. Simulation is defined as a technique or activity that aims to "authentically recreate, imitate or amplify characteristics, processes and experiences of the real world for the purposes of teaching, acquiring and assessing knowledge, skills and attitudes" ([18], p. 411). Simulation exercises are developed on a continuum from low fidelity to high fidelity [19] and activities include the use of standardised patients (SPs) with actors or real patients, high-fidelity patients such as mannequins, or virtual clinical exercises [20] [21]. Low fidelity patient simulation refers to case studies or simple psychomotor skills. Medium (or intermediate) fidelity involves manikins that have a basic level of computerisation with minimal realism or complexity. High fidelity patient simulation refers to pre-developed realistic patient scenarios and computerised manikins, also termed a high-fidelity manikin, that are able to respond to student nursing interventions [22]. Each of these approaches offers possibilities in preparing student nurses' for suicide risk assessment.

\section{Aim}

The aim of this paper is to explore the potential of simulation in preparing student nurses for suicide risk assessment. 


\section{Method}

A computer search of databases was undertaken through CINAHL, Medline, and Proquest Nursing and Allied Health Source. The search terms "undergraduate nursing education" and "suicide" and "simulation" yielded few articles. Given a lack of literature, and that experiencing a mental disorder is one of the strongest risk factors for suicide [23], the search was expanded to cover the use of mental health simulations to educate undergraduate nurses how to work alongside people with experiences of mental illness. Key search words added were "mental health" and "mental illness". This yielded a larger number of articles published between 2007 and 2016. The inclusion criteria were articles that were: (i) published in peer reviewed journals; (ii) original research (iii) written in English; and (iv) reported, investigated or contained results related to the focus of this paper. Exclusion criteria included: (i) studies not using simulation modalities; (ii) those focused on physical assessment (iii) and those specifically related to other professional student groupings, for example medical students. Hand searches of references of relevant articles and a search of Google Scholar identified further articles which could be included (Figure 1).

In order to attain the aim of this article the content of the articles were initially scrutinised to identify key themes. Then the following analytical questions were formulated: (i) What simulation modalities have been employed and what outcomes are associated with these (Table 1)? (ii) What are the implications for supporting student nurses to develop skills in suicide risk assessment? (iii) What are the implications for nursing education? The findings from this analysis are discussed in the following sections.

\section{Simulation Modalities}

\subsection{Standardised Patients}

The use of standardised patients [SPs] within simulation is one of the more

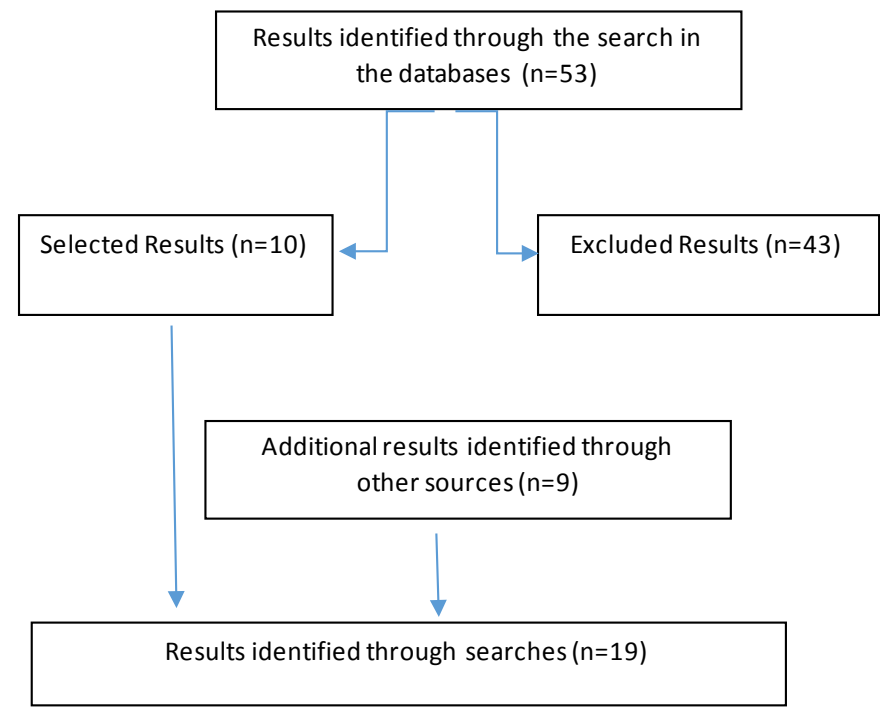

Figure 1. Selection process flowchart. 
Table 1. Simulation modalities in undergraduate mental health nursing education.

\begin{tabular}{|c|c|c|c|c|}
\hline $\begin{array}{l}\text { Author } \\
\text { Reference }\end{array}$ & Design & Aim & Modality & Outcomes \\
\hline $\begin{array}{l}\text { Bartlett \& Butson } \\
\quad(2015)[27]\end{array}$ & $\begin{array}{l}\text { Survey } \\
\mathrm{N}=44\end{array}$ & $\begin{array}{l}\text { Describes the use of actor-based simulations in mental health educa- } \\
\text { tion }\end{array}$ & SP & CA; DA; EC; IC \\
\hline $\begin{array}{l}\text { Dearing \& Steadman } \\
\quad(2008)[34]\end{array}$ & $\begin{array}{l}\text { Experimental } \\
\text { Comparative } \\
\text { Post test } \mathrm{N}=94\end{array}$ & $\begin{array}{c}\text { To determine the success of a VHS during orientation in changing } \\
\text { nursing students' attitudes regarding patients who experience } \\
\text { auditory hallucinations }\end{array}$ & VHS & CA; IE \\
\hline $\begin{array}{l}\text { Doolen et al. (2014) } \\
\qquad[24]\end{array}$ & $\begin{array}{l}\text { Survey } \\
\mathrm{N}=94\end{array}$ & Describes the development and use of SPs as a learning strategy & SP & DA; EC; IC; RE \\
\hline $\begin{array}{l}\text { Evans et al. (2015) } \\
\text { [35] }\end{array}$ & $\begin{array}{l}\text { Quasi-experimental } \\
\text { pre-post test } \\
\mathrm{N}=256\end{array}$ & $\begin{array}{l}\text { To evaluate whether students' participation in a simulated auditory } \\
\text { hallucination will increase their understanding and knowledge about } \\
\text { psychosis and auditory hallucinations }\end{array}$ & VHS & IE; IU \\
\hline $\begin{array}{l}\text { Hamilton Wilson } \\
\text { et al. (2009) [37] }\end{array}$ & $\begin{array}{l}\text { Narrative } \\
\mathrm{N}=27\end{array}$ & $\begin{array}{l}\text { To provide nursing students with an experiential learning opportu- } \\
\text { nity which simulated living with voice hearing }\end{array}$ & VHS & IE; IU \\
\hline $\begin{array}{l}\text { Hermanns et al. } \\
\quad(2011)[41]\end{array}$ & $\begin{array}{l}\text { Evaluation } \\
\qquad \mathrm{N}=11\end{array}$ & $\begin{array}{l}\text { To illustrate the use of a simulated attempted suicide scenario in a } \\
\text { psychiatric inpatient setting. }\end{array}$ & MHF & IU; SE \\
\hline $\begin{array}{l}\text { Jack et al. (2014) } \\
\quad[12]\end{array}$ & Descriptive & $\begin{array}{l}\text { To describe the implementation of simulation using a professional } \\
\text { actor to prepare students for clinical rotation }\end{array}$ & SP & EC; IC \\
\hline $\begin{array}{l}\text { Kameg et al. (2013) } \\
\text { [39] }\end{array}$ & $\begin{array}{l}\text { Quasi-experimental } \\
\text { Pre - post test } \\
\quad \mathrm{N}=37\end{array}$ & $\begin{array}{l}\text { To assess if High Fidelity Patient Simulation improved student } \\
\text { knowledge and retention of knowledge }\end{array}$ & MHF & IK; IS \\
\hline $\begin{array}{l}\text { Kameg et al. (2014). } \\
\qquad[28]\end{array}$ & $\begin{array}{l}\text { Quasi-Experimental } \\
\qquad \mathrm{N}=69\end{array}$ & $\begin{array}{l}\text { To assess if SPs can reduce student anxiety as measured by an anxie- } \\
\text { ty visual analog scale }\end{array}$ & SP & DA; EC; IC \\
\hline $\begin{array}{l}\text { Kidd et al. (2012) } \\
\text { [33] }\end{array}$ & $\begin{array}{c}\text { Survey } \\
\mathrm{N}=126\end{array}$ & $\begin{array}{l}\text { To measure the effectiveness of a Second Life virtual simulation as a } \\
\text { teaching strategy }\end{array}$ & VT & EG; FL; SE \\
\hline $\begin{array}{l}\text { Lambert \& Watkins } \\
\qquad(2013)[32]\end{array}$ & Descriptive & $\begin{array}{l}\text { To describe how a cohort of students undertook a simulation project } \\
\text { following a virtual patient to an acute inpatient ward. }\end{array}$ & VT & CT; EC \\
\hline $\begin{array}{l}\text { Lehr \& Kaplan } \\
\quad(2013)[40]\end{array}$ & $\begin{array}{l}\text { Post - Survey } \\
\qquad \mathrm{N}=54\end{array}$ & $\begin{array}{l}\text { To assess the impact of a mental ealth simulation using a Medical } \\
\text { Education Technologies, Inc Simulation Effectiveness Tool. }\end{array}$ & MHF & DA; IU \\
\hline $\begin{array}{l}\text { Luebbert \& Popkess } \\
\qquad(2015)[25]\end{array}$ & $\begin{array}{l}\text { Experiemental, } \\
\text { two-group post-test } \\
\quad \mathrm{N}=34\end{array}$ & $\begin{array}{l}\text { To develop and test an innovative learning strategy using simulated } \\
\text { standardized patients to determine its effectiveness in teaching sui- } \\
\text { cide assessment skills }\end{array}$ & SP & CA; IC; RE; SE \\
\hline $\begin{array}{l}\text { Martin \& Chanda } \\
\quad(2016)[26]\end{array}$ & $\begin{array}{l}\text { Quasi-experimental, one } \\
\text { group, pre-post test } \\
\mathrm{N}=28\end{array}$ & $\begin{array}{l}\text { To describe a mental health simulation that encourages the use of } \\
\text { therapeutic communication in a mental health setting }\end{array}$ & SP & EC; RE \\
\hline Mason (2014) [36] & $\begin{array}{l}\text { A pre-post test } \\
\qquad \mathrm{N}=60\end{array}$ & $\begin{array}{l}\text { To determine if media technology contributes towards an increase in } \\
\text { knowledge, empathy and a change in attitudes in regards to auditory } \\
\text { hallucinations }\end{array}$ & VHS & IE; IU \\
\hline Orr et al. (2013) [38] & $\begin{array}{l}\text { Questionnaire } \\
\qquad \mathrm{N}=76\end{array}$ & $\begin{array}{l}\text { To develop and assess simulated voice-hearing as an alternative } \\
\text { learning tool to promote a deeper understanding of voice hearing } \\
\text { and communication skills }\end{array}$ & VHS & EC; IE; IU \\
\hline $\begin{array}{l}\text { Robinson-Smith et } \\
\text { al. (2009) [29] }\end{array}$ & $\begin{array}{l}\text { Survey, } \\
\mathrm{N}=112\end{array}$ & $\begin{array}{l}\text { To develop and evaluate nursing students' satisfaction with an SP } \\
\text { pyschiatric clinical encounter in which students performed a mental } \\
\text { status exam and suicidal risk assessment }\end{array}$ & SP & $\begin{array}{l}\text { CT; EC; } \\
\text { IC; IS }\end{array}$ \\
\hline Webster (2013) [30] & Descriptive & $\begin{array}{l}\text { To incorporate the Quality and Safety Education for Nurses compe- } \\
\text { tency into a simulation activity aimed to improve therapeutic com- } \\
\text { munication skills in psychiatric nursing }\end{array}$ & SP & $\mathrm{EC}$ \\
\hline $\begin{array}{l}\text { Yong-Shian et al. } \\
\quad(2016)[31]\end{array}$ & $\begin{array}{l}\text { Quasi-experimental, } \\
\text { pre-post test } \mathrm{N}=95\end{array}$ & $\begin{array}{l}\text { To explore the learning experience of nursing students using SPs } \\
\text { whilst practising their mental status examination and suicide risk } \\
\text { assessment skills. }\end{array}$ & SP & CA; EC; IC: RE \\
\hline
\end{tabular}

Outcomes Key: CA, Change Attitudes; CT, Critical Thinking; DA, Decrease Anxiety; EC, Enhance Communication; EG, Engagement; FL, Flexibility; IC, Improve Confidence; IE, Increase Empathy; IK, Increase Knowledge; IS, Increase Satisfaction; IU, Increase Understanding; MFS, Medium-High Fidelity Simulation; RE, Realistic Environment; SE, Safe Environment; SP, Standardized Patients; VHS, Voice Hearing Simulation; VP, Virtual Technology. 
common approaches in the research available and has the advantage of supporting communication with actual people. It is seen to promote a more realistic environment for students [24] [25] [26]. The SP realistically acts a person experiencing mental distress by portraying a range of human responses such as behavioural, physical, psychological and emotional expressions, enabling verbal and non-verbal cues in communication to be assessed and acted upon [24] [27] [28]. This was supported by other studies using SPs, who had similar findings in their studies of mental health nursing students and an SP (a professional actor), emphasising the opportunity for students to observe and develop therapeutic communication skills [12] [26] [29] [30].

The use of SPs can support a decrease in anxiety, increase in confidence and provide a safe environment to practice skills including communication skills. Bartlett and Butson [27] found in their study of actor-based simulations that these helped demystify the mental health clinical setting and provided a rich learning environment for development of student's mental health nursing skills. Studies also found a simulated environment using SPs enables nursing students to increase their confidence and decrease their anxiety [24] [28] and improved student nurses confidence and attitudes towards engaging with a person who is suicidal [12] [25] [27] [29] [31]. Robinson-Smith et al. [29] surveyed 112 undergraduate nurses on their self-confidence, critical thinking skills and satisfaction with learning following a standardised patient simulation in which students had to undertake a suicide risk assessment. Overall the students' self-confidence, critical thinking and satisfaction with the learning increased. However, the authors noted that the students risk assessments were undeveloped and did not cover all aspects for reducing risks for suicide. Luebbert and Popkess [25] study of 34 nursing students, also found the use of standardised patients provided a safe alternative for students to practice suicide assessment skills prior to entering the clinical environment. In their study half the nursing students (control group) were given a lecture format on suicide assessment, and the other group (Intervention group) interviewed standardised patients with depression and suicide risk. As noted above, in comparison to the control group, the intervention group reported higher levels of student satisfaction about the learning activity and selfconfidence although knowledge between the groups did not differ.

Preparation of SPs and constructive feedback on student performance from SPs was a key aspect of many of the SP studies. Robinson-Smith et al. [29] found that these two elements were an essential aspect of SP simulation. Bartlett et al. [27] also found that inadequate SP training and limited understanding of mental health experiences can impact on the realism of the simulation and student learning. Authenticity is also dependent on the SP keeping within the simulation design [26].

\subsection{Virtual Technologies}

Virtual technology is an example of a small but growing simulation approach that does not require interaction with actual people. Virtual technologies such as 
use of avatar programmes appear to allow students to practice skills by accessing learning environments that are convenient and flexible to time needs. Lambert and Watkins [32] developed a project which incorporated a virtual patient (in the form of anavatar-an animated human representation) called Mohammed. In this simulation project, 85 first year mental health nursing students followed the admission of a virtual patient to an acute inpatient ward. Over a two week period the student nurses engaged with Mohammed both individually and in teams to support his recovery. The simulation provided the students with opportunities to develop their communication skills and also their clinical reasoning and critical thinking skills. Students reported a greater level of engagement with what were initially perceived as challenging learning activities. In another study [33] students had the opportunity to assess and communicate with a client in the virtual environment of 'second life'. This provided a safe environment as well as flexibility; however technical issues such as older computers and internet connections and lack of realism did limit the effectiveness of their virtual reality programme.

\subsection{Voice Hearing Simulations}

Voice-hearing simulations is another example of a simulation approach that although not widely used in undergraduate education, in mental health it does appear to have a valuable role in challenging stigmatising attitudes and stereotypes, promoting understanding and empathy, and increasing knowledge. Dearing and Steadman [34] found the utilisation of a voice simulation exercise (VSE) was an effective tool in reducing stigmatising attitudes and enhancing empathy. In their research, they compared the attitudes of nursing students who had listened to an audiotaped presentation of auditory hallucinations (experimental group), with those who had not received the experience (control group). The experimental group reported gaining more valuable insights or an "insider's view" into a voice hearer's world and were more empathetic and confident in their ability to develop a therapeutic relationship with people experiencing mental distress ([34], p. 65). Increased empathy as well as understanding was also supported by findings in recent studies by Evans et al. [35] and Mawson [36] who used iPods to enable students to experience auditory hallucinations during a simulated interview situation. Hamilton Wilson et al. [37] found that after a voice-hearing simulation workshop nursing students also described having gained an increased understanding into the challenges faced by people who hear voices. Similarly in a later study, Orr et al. [38] found that nursing students who had undertaken a voice-simulated exercise with $\mathrm{mp3}$ 's, reported better understanding of the reality of voice-hearers experiences, were more empathetic and were able to identify communication skills needed to engage with a voice-hearer.

\subsection{Medium-High Fidelity Simulation}

With the trend towards the introduction of medium-high fidelity simulation in undergraduate nursing education there has been some attempt to apply this to 
the area of mental health. Kameg et al. [39] used a high fidelity patient simulation to expose 37 students to a range of medical simulations incorporating a mental health assessment. However, although student knowledge improved, active engagement with the client was limited due to the "patient" inability to portray non-verbal communication. Lehr and Kaplan [40] found that student anxiety was reduced following high fidelity simulations with clients presenting in an emergency room and a surgical ward scenario. Fifty-four students were involved in the simulation although not all were active participants. The combined physical and mental health assessment supported integration of mental and physical assessment skills. In a small study of ten students Hermanns et al. [41] replicated an attempted suicide scenario in an inpatient mental health setting. The focus was on resuscitation of a non-interactive mannequin with cues to patient physical status from faculty acting as staff. This scenario enabled students to practice emergency responses in a safe environment.

\section{Supporting Nursing Students for Suicide Risk Assessment}

At the heart of effective suicide risk assessment is changing attitudes of nurses towards people who are suicidal, increasing confidence and improving assessment skills. It is apparent that SPs, medium-high fidelity, virtual and voice simulation modalities all have the potential to change attitudes and decrease stigma. As future professional gate-keepers or clinicians who are likely to come into contact with at-risk people [10] it is critical that negative attitudes are challenged and addressed. Increasing confidence is especially important for student nurses as they often report feeling anxious talking with someone who is suicidal for fear that they may say the wrong thing and make matters worse [42]. This then impacts on student's confidence to communicate effectively, establish therapeutic relationships, and assess for suicidal risk [43]. Establishing a rapport is central to supporting clients to disclose relevant information and assists clients at risk to feel connected and more positive about their situation [6] [44].

Increased knowledge and understanding was a benefit of many of the studies using different simulation modalities. However, Hayden et al. [45] found that simulation in general does not appear to significantly improve nursing knowledge. This was supported by Luebbert and Popkess's study [25] which found that there were no reported differences in knowledge about suicide assessment between the control and intervention group. However, the authors suggest that the tools used to measure knowledge acquisition do not fully capture the different levels of learning that occur during simulation exercises, and future studies need to explore the various types of knowledge, beyond factual knowledge, that is acquired during actor based simulations.

Suicide risk assessment involves a number of skills and as mentioned previously can take the form of a mental health assessment or suicide risk assessment involving direct questioning about suicidality [6]. The studies covering suicide risk assessment used mental status examinations incorporating questioning to identify suicidal risk [12] [27] [29] [31] and non-specific interviewing 
or questioning [24] [25] [28] [30]. Apart from one study all viewed development of communication skills as a key outcome. Of most importance in a mental health nursing assessment is engagement with the client [44]. Acquired knowledge may not necessary translate into practical skills. Osteen et al. [10] identified in their review of suicide prevention training for health professionals that skills-based training needed to be a critical component of any training programme. This should incorporate the ability to question and respond to warning cues. The use of standardised patients and role plays were identified as more effective then didactic learning approaches to develop these skills.

Incorporating simulation to reflect a realistic environment for suicide risk assessment is a challenge especially as attending to non-verbal communication of clients and practicing therapeutic communication is key to effective assessment. According to Haynal-Reymond et al. [46] non-verbal cues from clients at risk of suicide provides vital information in assessing suicide risk. Therapeutic engagement between nurses and clients at risk of suicide is seen as the most central factor in nursing management [47] [48]. However, in practice there is evidence that very little engagement occurs, due in part to lack of preparation for this competency in nursing education [48].

Simulation has the potential to support development of this key competency. In general it has been reported to improve student nurses' communication skills [49]. SP simulations can be critical in the development of therapeutic communication as students are able to identify the effectiveness of their communication skills because of how the SP responds to their interpersonal communication approaches [26]. Although high fidelity manikins promote a safe environment in which students can develop their clinical skills and decision making [43], highfidelity manikins are unable to simulate the complexity of human behaviours, such as mood, emotions, facial expressions and body language [24] [27]. In addition, the realism of the simulation to the clinical environment is central to quality learning [50]. Students have difficulty viewing the mannequin as "rea" or as helpful in developing a client-nurse interpersonal relationship [51] and in the case of computerised mannequins are not able to use all their senses, including those of smell and touch [50]. The use of SPs appears to be the simulation modality with the most potential to promote use of the full range of human communication including non-verbal communication. A sense of realism and incorporation of expressive behaviours and responses give insight into the person's experience and are critical in the assessment of a person's mental health needs, including suicide risk assessment.

\section{Implications for Nursing Education}

If we are to be serious about reducing the suicide statistics and meet the directive from the WHO for suicide risk assessment to be a core competency of nurses we must begin at the undergraduate level. As outlined previously capability with both mental health assessment and suicide risk assessment prepares frontline staff to act to prevent suicide. Simulation does offer one approach to meeting 
this goal for nursing. The limited number of studies related specifically to the use of simulation and suicidality may primarily be a reflection of this being a newer area of study. Within nursing curriculum, the design of mental health simulations is a relatively new and innovative educational tool and it is acknowledged that more research on the effectiveness of simulation is needed [21] [52]. Within society there is also generally a reluctance to discuss matters associated with death and dying [53]. The lack of research literature related specifically to the use of simulation and suicidality may covertly reflect society's and therefore nurses reluctance to engage with this social taboo topic. Such concerns may be replicated within nursing curriculum and possibly contribute to the minimal number of simulation exercises on this topic.

Some simulation modalities such as voice simulation offer more flexibility and have less resource implications. There is also increasing demand to respond to modern-day technologies such as virtual learning environments to support student preparation for practice [54]. The use of simulation has arisen in a changing educational environment, where nurse educators need to manage conflicting tensions surrounding more flexible on-line web based programmes with reduced face-to face teaching hours and budgets [32]. Simulations can be expensive to resource, both financially and in time. But given the positive educational advantages over traditional pedagogy methods, the cost of simulations may be worth it, as the results, especially in the area of suicide risk assessment, can be lifesaving.

In an ideal world we would expose students to a range of simulation modalities focusing on mental health and incorporate a suicide assessment as one of these. However, if the ability to integrate multiple simulations is not possible it appears that a suicide risk assessment scenario incorporating SPs would achieve results that other modalities would achieve but at the same time be inclusive of key non-verbal communication skills and promote authenticity. The few simulations focusing on suicide predominantly used Standardised Patients (SPs) for this reason. The simulations were designed specifically to educate nursing students about suicide risk, enhance nursing students confidence, lessen anxieties and stigmatising attitudes, and help develop therapeutic communication skills [12] [25] [27] [29] [31]. Positive feedback about actor based simulations for suicide assessment training for mental health professional has also been noted in earlier studies [55] [56]. As identified earlier, one consideration is that preparation of the SP is crucial to an effective simulation to ensure authentic behaviour [26]. In addition, the portrayal of a person experiencing mental distress can be emotionally challenging and potentially harmful. In order to protect the psychological welfare of the SP, the actors should be trained not to draw upon their own personal experience but rather to keep to the parameters of the scenario [57].

Regardless of the simulation modality, debriefing and/or follow up sessions were also themes emerging in the studies and should be incorporated into a suicide risk assessment simulation. Debriefing is standard in many simulation 
modalities and structured debriefing is seen as essential to learning (Fey \& Jenkins 2015; Webster 2013), even if it is time intensive [30] [58]. Other approaches associated with high fidelity simulation such as group observation via video streaming can also be incorporated [24]. According to Oudshoorn and Sinclair [59] the development of skills to cope with mental health challenges and to prepare for a suicide risk assessment cannot be achieved in one attempt. Osteen et al. [10] also identified follow-up sessions as critical to support initial training in working with clients at-risk of suicide.

Nurses will encounter and must be prepared to identify and respond to clients who are potentially suicidal regardless of the clinical setting. The pathway to becoming a registered nurse in New Zealand is by undertaking a Bachelor of Nursing programme. Upon completion of their programme, nursing graduates are deemed competent to provide safe nursing care. One area of competency involves undertaking a comprehensive and accurate nursing assessment in a variety of health settings [60]. Physical needs of clients cannot be separated from their mental health needs [39] [40]. However, nearly all the simulations identified in this paper incorporating suicide risk assessment were located within a mental health setting [12] [24] [25] [27] [28] [29] [30]. There is an international trend towards preparing front line staff to respond to client's mental health needs regardless of the setting. The World Health Organisation released guidelines for health professional working in primary care and accident and emergency settings to work with those with mental health challenges [61]. Currently in New Zealand primary health care nurses are undertaking credentialing programmes to update their mental health and addiction skills and knowledge so they are able to be recognise and be responsive to clients with these needs [62]. In addition guidelines for suicide risk assessment have been released for emergency departments [5]. To prepare nursing students for current practice, simulations incorporating suicide risk assessment need to be located not just within a specific mental health context but also a wider range of clinical settings.

It is apparent that further research is required on the potential of simulation modalities to prepare students for suicide risk assessment especially in the area of therapeutic interpersonal communication. Further research on simulation which integrates mental health into a variety of clinical areas would support the preparation of nurses to carry out mental health assessment regardless of the setting. It would also be beneficial to explore the cost-effectiveness of different simulation modalities.

\section{Conclusion}

The aim of this paper was to explore the potential of simulation in preparing student nurses for suicide risk assessment. It is apparent that all modalities to greater or lesser degrees have the potential to decrease student anxiety, promote student confidence, communication skills, and knowledge and understanding in working with clients at risk of suicide. The use of SP simulations supports students to practice in a manner in which the full range of authentic human expres- 
sion and communication can be enacted and experienced. A well designed simulation package including preparation, feedback and ongoing reinforcement and integrating multiple clinical settings offers the most potential to support student nurses to be prepared for suicide risk assessment. In light of the increasing focus on technology based simulations, and emphasis on flexibility and cost reduction, it would be prudent for nurse educators to remember what skills are most central to effective suicide risk assessment when introducing simulation to develop skills in this area of practice.

\section{Relevance for Clinical Practice}

Suicide is preventable, and nurses are in a key position to prevent suicide. However, nurses report feeling unconfident in assessing for suicide risk. Development of these potentially life-saving skills needs to start at the undergraduate level. The findings of this paper identify the potential of different simulation modalities in educating our future nurses in suicide risk assessment. The findings also reveal that most undergraduate simulations regarding suicide risk, tend to be focused primarily within a mental health setting. Given that nurses are likely to encounter a person who is suicidal in any clinical area, simulation scenarios may need to be located within a wide range of clinical settings. This paper highlights that regardless of the setting, nurses need to have the knowledge, confidence and skills in assessing for suicide risk. Simulation is one approach to support acquisition of these skills.

\section{References}

[1] World Health Organisation (2014) Preventing Suicide: A Global Imperative. http://www.who.int/mediacentre/news/releases/2014/suicide-prevention-report/en/.

[2] Ministry of Health (2015) Understanding Suicide in New Zealand. http://www.health.govt.nz/our-work/mental-health-and-addictions/working-preven t-suicide/understanding-suicide-new-zealand\#suiciderates.

[3] Ministry of Justice (2016) Chief Coroner Releases Provisional Annual Suicide Figures for the 2015/16 Year.

http://coronialservices.justice.govt.nz/assets/Documents/Publications/2016-provisio nal-coronial-suicide-stats-media-release.pdf.

[4] World Health Organisation (2013) Mental Health Action Plan 2013-2020. http://www.who.int/mental health/publications/action plan/en/.

[5] Ministry of Health (2016) Preventing Suicide: Guidance for Emergency Departments.

http://www.health.govt.nz/publication/preventing-suicide-guidance-emergency-dep artments

[6] New Zealand Guidelines Group and Ministry of Health (2003) The Assessment and Management of People at Risk of Suicide: Best Practice Evidence-Based Guideline. http://www.health.govt.nz/publication/assessment-and-management-people-risk-su icide.

[7] Feldman, M., Frank, P., Duberstein, P., Vannoy, S., Epstein, R. and Kravitz, R. (2009) Let's Not Talk about It: Suicide Inquiry in Primary Care. Annals of Family Medicine, 5, 412-418. https://doi.org/10.1370/afm.719 
[8] Hamer, H., Lampshire, D. and Thomson, S. (2014) Mental Health of Older People. In: Procter, N., Hamer, H., Mcgarry, D., Wilson, R. and Foggart, T., Eds., Mental Health a Person Centred Approach, Cambridge University Press, Melbourne, Australia, 267-286.

[9] Bolster, C., Holliday, C., Oneal, G. and Shaw, M. (2015) Suicide Assessment and Nurses: What Does the Evidence Show? Online Journal of Issues in Nursing, 20, $1-11$.

[10] Osteen, P.J., Frey, J.J. and Ko, J. (2014) Advancing Training to Identify, Intervene and Follow Up Individuals at Risk for Suicide through Research. American Journal of Preventive Medicine, 47, 216-221. https://doi.org/10.1016/j.amepre.2014.05.033

[11] Pullen, J.M., Gilje, F. and Tesar, E. (2016) A Descriptive Study of Baccalaureate Nursing Students' Responses to Suicide Prevention Education. Nurse Education in Practice, 16, 104-110. https://doi.org/10.1016/j.nepr.2015.09.007

[12] Jack, D., Gerolamo, A.M., Frederick, D., Szajna, A. and Muccitelli, J. (2014) Using Trained Actors to Model Mental Health Nursing Care. Clinical Simulation in Nursing, 10, 515-520. https://doi.org/10.1016/j.ecns.2014.06.003

[13] Kawanishi, C., Sato, R., Yamada, T., Ikeda, S.A. and Hirayasu, Y. (2006) Knowledge and Attitudes of Nurses, Nursing Students and Psychiatric, Social Workers Concerning Current Suicide-Related Issues in Japan. Primary Care Mental Health, 4, 285-292.

[14] Pederson, C. (1993) Promoting Nursing Students' Positive Attitudes towards Providing Care for Suicidal Patients. Issues in Mental Health Nursing, 14, 67-84. https://doi.org/10.3109/01612849309006891

[15] Samuelsson, M. and Asberg, M. (2002) Training Program in Suicide Prevention for Psychiatric Nursing Personnel Enhance Attitudes to Attempted Suicide Patients. International Journal of Nursing Studies, 39, 115-121. https://doi.org/10.1016/S0020-7489(00)00110-3

[16] Sun, F.-K., Long, A., Hung, X.-Y. and Chiang, C.-Y. (2011) A Quasi-Experimental Investigation into the Efficacy of a Suicide Education Programme for Second-Year Student Nurses in Taiwan. Journal of Clinical Nursing, 20, 837-846. https://doi.org/10.1111/j.1365-2702.2010.03503.x

[17] Heyman, I., Webster, B.J. and Tee, S. (2015) Curriculum Development through Understanding the Student Nurse Experience of Suicide Intervention Education-A Phenomenographic Study. Nurse Education in Practice, 15, 498-506. https://doi.org/10.1016/j.nepr.2015.04.008

[18] Guise, V., Chambers, M. and Valimaki, M. (2012) What Can Virtual Patient Simulation Offer Mental Health Education? Journal of Psychiatric and Mental Health Nursing, 19, 410-418. https://doi.org/10.1111/j.1365-2850.2011.01797.x

[19] Tosterud, R., Hedelin, B. and Hall-Lord, M. (2013) Nursing Students' Perceptions of High- and Low-Fidelity Simulation Used as Learning Methods. Nurse Education in Practice, 13, 262-270. https://doi.org/10.1016/j.nepr.2013.02.002

[20] Brown, J. (2008) Applications of Simulation in Psychiatric Mental Health Nursing Education. Journal of Psychiatric and Mental Health Nursing, 15, 638-644. https://doi.org/10.1111/j.1365-2850.2008.001281.x

[21] Brown, A.M. (2015) Simulation in Undergraduate Mental Health Nursing Education: A Literature Review. Clinical Simulation in Nursing, 11, 445-449. https://doi.org/10.1016/j.ecns.2015.08.003

[22] Weaver, A. (2011) High-Fidelity Patient Simulation in Nursing Education: An Integrative Review. Nursing Education Perspectives, 32, 37-40. 
https://doi.org/10.5480/1536-5026-32.1.37

[23] Ministry of Health (2015) Suicide Prevention Toolkit for District Health Boards. http://www.health.govt.nz/publication/suicide-prevention-toolkit-district-health-bo $\underline{\operatorname{ards}}$

[24] Doolen, J., Giddings, M., Johnson, M., de Nathan, G.G. and O Badia, L. (2014) An Evaluation of Mental Health Simulation with Standardized Patients. International Journal of Nursing Education Scholarship, 11, 55-62. https://doi.org/10.1515/ijnes-2013-0075

[25] Luebbert, R. and Popkess, A. (2015) The Influence of Teaching Method on Performance of Suicide Assessment in Baccalaureate Nursing Students. Journal of the American Psychiatric Nurses Association, 21, 126-133. https://doi.org/10.1177/1078390315580096

[26] Martin, C.T. and Chanda, N. (2016) Mental Health Clinical Simulation: Therapeutic Communication. Clinical Simulation in Nursing, 12, 209-214. https://doi.org/10.1016/j.ecns.2016.02.007

[27] Bartlett, S. and Butson, R. (2015) Trained Actors Help Students Learn Mental Health Nursing Skills. Kai Tiaki Nursing New Zealand, 21, 17-19.

[28] Kameg, K.M., Szpak, J.L., Cline, T.W. and Mcdermott, D.S. (2014) Utilization of Standardized Patients to Decrease Nursing Student Anxiety. Clinical Simulation in Nursing, 10, 567-573. https://doi.org/10.1016/j.ecns.2014.09.006

[29] Robinson-Smith, G., Bradley, P.K. and Meakim, C. (2009) Evaluating the Use of Standardised Patients in Undergraduate Psychiatric Nursing Experiences. Clinical Simulation in Nursing, 5, e203-e211. https://doi.org/10.1016/j.ecns.2009.07.001

[30] Webster, D. (2013) Promoting Therapeutic Communication and Patient-Centered Care Using Standardized Patients. Journal of Nursing Education, 52, 645-648. https://doi.org/10.3928/01484834-20131014-06

[31] Yong-Shian, G.O.H., Selvarajan, S., Chng, M.L., Tan, C.S. and Yobas, P. (2016) Using Standardized Patients in Enhancing Undergraduate Students' Learning Experience in Mental Health Nursing. Nurse Education Today, 45, 167-172. https://doi.org/10.1016/j.nedt.2016.08.005

[32] Lambert, N. and Watkins, L. (2013) Meet Mohammed: Using Simulation and Technology to Support Learning. The Journal of Mental Health Training, Education and Practice, 8, 66-75. https://doi.org/10.1108/JMHTEP-03-2012-0001

[33] Kidd, L., Kinsley, S. and Morgan, K. (2012) Effectiveness of a Second Life? Simulation as a Teaching Strategy for Undergraduate Mental Health Nursing Students. Journal of Psychosocial Nursing \& Mental Health Services, 50, 28-37. https://doi.org/10.3928/02793695-20120605-04

[34] Dearing, K.S. and Steadman, S. (2008) Challenging Stereotyping and Bias: A voice Simulation Study. Journal of Nursing Education, 47, 59-65. https://doi.org/10.3928/01484834-20080201-07

[35] Evans, J., Webster, S., Gallagher, S., Brown, P. and Sinclair, J. (2015) Simulation in Nursing Education: iPod as a Teaching Tool for Undergraduate Nurses. Issues in Mental Health Nursing, 36, 505-512. https://doi.org/10.3109/01612840.2014.1003667

[36] Mawson, K. (2014) Use of Media Technology to Enhance the Learning of Student Nurses in Regards to Auditory Hallucinations. International Journal of Mental Health Nursing, 23, 135-144. https://doi.org/10.1111/inm.12031

[37] Hamilton Wilson, J.E., Azzopardi, W., Sager, S., Gould, B., Conroy, S., Deegan, P. and Archie, S. (2009) A Narrative Study of the Experiences of Student Nurses Who 
Have Participated in the Hearing Voices That Are Distressing Simulation. International Journal of Nursing Education Scholarship, 6, 19-25. https://doi.org/10.2202/1548-923X.1727

[38] Orr, F., Kellehear, K., Armani, E., Pearson, A. and Douglas, H. (2013) The Distress of Voice-Hearing: The Use of Simulation for Awareness, Understanding and Communication Skill Development in Undergraduate Nursing Education. Nurse Education in Practice, 13, 529-535. https://doi.org/10.1016/j.nepr.2013.03.023

[39] Kameg, K.M., Englert, N.C., Howard, V.M. and Perozzi, K.J. (2013) Fusion of Psychiatric and Medical High Fidelity Patient Simulation Scenarios: Effect on Nursing Student Knowledge, Retention of Knowledge, and Perception. Issues in Mental Health Nursing, 34, 892-900. https://doi.org/10.3109/01612840.2013.854543

[40] Lehr, S.T. and Kaplan, B. (2013) A Mental Health Simulation Experience for Baccalaureate Student Nurses. Clinical Simulation in Nursing, 9, e425-e431. https://doi.org/10.1016/j.ecns.2012.12.003

[41] Hermanns, B., Lilly, M.L. and Crawley, B. (2011) Using Clinical Simulation to Enhance Psychiatric Nursing Training of Baccalaureate Students. Clinical Simulation in Nursing, 7, e41-e46. https://doi.org/10.1016/j.ecns.2010.05.001

[42] Scheckel, M.M. and Nelson, K.A. (2014) An Interpretive Study of Nursing Students' Experiences of Caring for Suicidal Persons. Journal of Professional Nursing, 30, 426-435. https://doi.org/10.1016/j.profnurs.2014.03.003

[43] Kameg, K., Mitchell, A., Clochesy, J., Howard, V. and Suresky, J. (2009) Communication and Human Patient Simulation in Psychiatric Nursing. Issues in Mental Health Nursing, 30, 503-508. https://doi.org/10.1080/01612840802601366

[44] Coombs, T., Curtis, J. and Crookes, P. (2013) What Is the Process of a Comprehensive Mental Health Nursing Assessment? Results from a Qualitative Study. International Nursing Review, 60, 96-102. https://doi.org/10.1111/j.1466-7657.2012.01036.x

[45] Hayden, J.K., Smiley, R.A., Alexander, M., Kardong-Edgren, S. and Jeffries, P.R. (2014) The NCSBN National Simulation Study: A Longitudinal, Randomized Controlled Study Replacing Clinical Hours with Simulation in Pre-Licensure Nursing Education. Journal of Nursing Regulation, 5, 3-64.

[46] Haynal-Reymond, V., Jonsson, G.K. and Magnusson, M.S. (2005) Non-Verbal Communication in Doctor-Suicidal Patient Interview. Emerging Communication, 7, 141 .

[47] Billings, C.V. (2004) Psychiatric Inpatient Suicide: Focus on Intervention. Journal of the American Psychiatric Nurse Association, 10, 190-192.

[48] Lees, D. (2013) Therapeutic Engagement between People Experiencing Suicidal Crisis and Mental Health Nurses. Doctoral Dissertation, University of Tasmania, Hobart.

[49] Foronda, C., Liu, S. and Bauman, E.B. (2013) Evaluation of Simulation in Undergraduate Nurse Education: An Integrative Review. Clinical Simulation in Nursing, 9, e409-e416. https://doi.org/10.1016/j.ecns.2012.11.003

[50] Roberts, D. and Roberts, N.J. (2014) Maximising Sensory Learning through Immersive Education. Journal of Nursing Education and Practice, 4, 74. https://doi.org/10.5430/jnep.v4n10p74

[51] Dean, S., Williams, C. and Balnaves, M. (2015) Practising on Plastic People: Can I Really Care? Contemporary Nurse, 51, 257-271. https://doi.org/10.1080/10376178.2016.1163231

[52] Campbell, S. and Daley, K. (2012) Simulation Scenarios for Nursing Education. 2nd Edition, Springer Publishing, New York. 
[53] Lundgren, B. and Houseman, C. (2010) Banishing Death: The Disappearance of the Appreciation of Mortality. Omega: Journal of Death \& Dying, 61, 223-249. https://doi.org/10.2190/OM.61.3.d

[54] Wilson, R. and Hungerford, C. (2015) Mental Health Education and Virtual Learning Environments (VLEs) in Pre-Registration Nursing Degrees: Follow the Leaders? Issues in Mental Health Nursing, 36, 379-387. https://doi.org/10.3109/01612840.2014.1002647

[55] Appleby, L., Morriss, R., Gask, L., Roland, M., Lewis, B., Perry, A., Battersby, L., Colbert, N., Green, G., Amos, T., Davies, L. and Faragher, B. (2000) An Educational Intervention for Front-Line Health Professionals in the Assessment and Management of Suicidal Patients (The STORM Project). Psychological Medicine, 30, 805812. https://doi.org/10.1017/S0033291799002494

[56] Fenwick, C.D., Vassilas, C.A., Carter, H. and Sayeed, H.M. (2004) Training Health Professionals in the Recognition, Assessment and Management of Suicide Risk. International Journal of Psychiatry in Clinical Practice, 8, 117-121. https://doi.org/10.1080/13651500410005658

[57] Keltner, N.L., Grant, J.S. and McLernon, D. (2011) Use of Actors as Standardized Psychiatric Patients. Journal of Psychosocial Nursing, 49, 35-40. https://doi.org/10.3928/02793695-20110329-02

[58] Fey, M.K. and Jenkins, L.S. (2015) Debriefing Practices in Nursing Education Programs: Results from a National Study. Nursing Education Perspectives, 36, 361-366. https://doi.org/10.5480/14-1520

[59] Oudshoorn, A. and Sinclair, B. (2015) Using Unfolding Simulations to Teach Mental Health Concepts in Undergraduate Nursing Education. Clinical Simulation in Nursing, 11, 396-401. https://doi.org/10.1016/j.ecns.2015.05.011

[60] Nursing Council of New Zealand (2014) Handbook for Nursing Departments Offering Programmes Leading to Registration as an Enrolled Nurse or Registered Nurse. http://www.nursingcouncil.org.nz/Education/Schools-Handbook

[61] World Health Organisation (2010) mhGAP Intervention Guide for Mental, Neurological and Substance Use Disorders in Non-Specialized Health Settings. http://www.who.int/mental health/publications/mhGAP intervention guide/en/

[62] Ministry of Health (2014) Mental Health and Addiction Credential in Primary Care. http://www.health.govt.nz/our-work/health-workforce/new-roles-and-initiatives/est ablished-initiatives/mental-health-and-addiction-credential-primary-care 
Submit or recommend next manuscript to SCIRP and we will provide best service for you:

Accepting pre-submission inquiries through Email, Facebook, LinkedIn, Twitter, etc. A wide selection of journals (inclusive of 9 subjects, more than 200 journals)

Providing 24-hour high-quality service

User-friendly online submission system

Fair and swift peer-review system

Efficient typesetting and proofreading procedure

Display of the result of downloads and visits, as well as the number of cited articles Maximum dissemination of your research work

Submit your manuscript at: http://papersubmission.scirp.org/

Or contact ojn@scirp.org 